\title{
Professional Function of Non-profit Research Facility
}

\author{
Yong Zhang ${ }^{1}$, Ping Lei ${ }^{2}$ \\ 1) School of Humanities \&Economic Management, China University Of Geosciences, NO. 29 Xueyuan Road, Beijing, China \\ ${ }^{2)}$ School of Humanities \&Economic Management, China University Of Geosciences, NO. 29 Xueyuan Road, Beijing, China
}

\begin{abstract}
Non-profit research facility construction on the one hand is to provide researchers a good research environment and hardware facilities, to enhance research and innovation capacity with providing tool support, on the other hand it should be used as means of public access, awareness, master of science and technology knowledge to improve their scientific and cultural level and overall scientific quality. And that it is the necessary measures to country promoting spiritual civilization and to improve the overall level of civilized society. This paper studies the science function orientation and professional function of non-profit research facilities. Aims to provide reasonable direction suggestion on professional function of non-profit research facility, making non-profit research facilities play a greater and more active role in terms of science popularization.
\end{abstract}

Keywords — public benefit, research facility, professional function

\section{公益类科研设施的科普功能承担研究}

\author{
张勇 $^{1}$ 雷平 $^{2}$ \\ 1) 中国地质大学 (北京) 人文经管学院, 学院路 29 号, 海淀, 北京, 中国 \\ 2) 中国地质大学 (北京) 人文经管学院, 学院路 29 号, 海淀, 北京, 中国
}

摘 要 公益类科研设施建设一方面是为科研人员提供良好的科研环境和硬件设施, 为提高科研创新能力提供工具保障, 另一方面 也应作为公众接触、认知、掌握科学技术知识, 提高自身科学文化水平和整体科学素质的媒介和手段, 同时也是一个国家加强精神文 明建设, 提高社会整体文明水平的必要举措。本文从公益类科研设施的科普功能定位、以及现有公益类科研设施的科普功能承担现状 展开研究, 旨在为公益类科研设施科普功能承担提供合理的方向建议, 使公益类科研设施在科学普及方面发挥更大、更积极的作用。

关键词 公益, 科研设施, 科普功能承担

\section{1. 相关概念界定}

1.1 公益类科研设施

所谓“公益”即公共利益, 具有不以盈利为目的, 惠及 全社会利益和福祉的社会属性; “科研设施”即由政府、社 会组织、个人提供的, 用于科学研究人员进行科学研究, 普通公众进行科学知识学习的设施、设备等工具; “公益类 科研设施”显然既具有公益类基础设施的公益性、非排他性 的社会属性, 同时也具有科研设施的共性特征, 且大多数 由政府提供, 为便于科学研究创新和科学知识普及而购置、 建立的器械、设备等科研基础设施。传统观念上的科研设
施一般被认为专业的科研人员即所谓的“内行”才能使用的 “专业”设备设施, 随着经济发展, 人们逐渐意识到, 科学 知识对于个人成长、国家强大、社会进步的重要性是显而 易见的, 科研设施不再只是科研人员的专属, 大力进行科 学知识普及, 让科学技术知识走进千家万户、寻常百姓家 对于公众科学素质提高, 生活条件改善具有重要作用和社 会现实性意义。

\section{2 科学普及}

西方的 “公众理解科学”在中国被称之为科学技术普

基金项目：教育部人文社会科学研究规划基金面上项目 “矿业投资环境研究”（12YJA790064）；国家自然科学基金面上项目 “产业 空间布局的资源环境效应：基于地方政府规制的研究”（41471112）；中央高校基本业务费优秀教师研究项目（2652015152） 
及。科学技术普及是指采用公众易于理解、接受和参与的 方式, 普及自然科学和社会科学知识, 传播科学思想, 弘 扬科学精神, 倡导科学方法, 推广科学技术应用的活动。 通过搜集整理科学真理, 用通俗易懂、寓教于乐的方式通 过相关媒介传播到受众人群的教育或教化。让公众理解科 学技术分为三个层次, 第一个层次是向公众普及科学知识、 科学观念和科学思想; 第二个层次是促使公众理解科学技 术本身的特点、发展规律、局限性以及科学技术和人类其 它活动的相互关系; 第三个层次是使公众理解科学的生命 在于创新, 理解自己是科学的主人, 从而参与到科学技术 的发明创造中来。

科普场馆和设施是面向社会公众进行科普宣传和教育 的重要场所。截止到 2001 年, 中国大陆地区共有科学技术 博物馆 240 多座, 包括科技馆 21 座, 综合性自然博物馆 8 座, 自然保护区建立的博物馆 6 座, 专业性自然史博物馆 115 座, 农业、航空、航天、邮电、铁路、中医药、煤炭、 军事等专业性技术博物馆约 50 座, 水族馆 38 座, 另有省 级综合性博物馆设立的自然部 9 座。

\section{2. 公益类科研设施科普功能承担现状}

\section{1 科研设施自身建设}

科研设施是指科研人员从事科学研究所需的资金、网 络设备、科研信息交流和成果共享的应用平台、实验基地、 文献检索体系等。科研环境的优良与否是一个国家和地区 的科研工作能否吸引人才、能否吸引投资、能否实现可持 续发展的重要基础, 而科研设施的建设发展不仅代表着这 个国家和地区的科研环境, 同时也影响制约着科学研究能 力。

改革开放以来, 我国经济建设迅猛发展, 取得很大成 功。国家对公益类科研设施的投入也在稳步增长。但是由 于公民对物质、文化、精神生活需求的提高同样迅速, 加 上我国人口基数太大的基本国情,用于公益类科研设施建设 的财政投入仍有很大空缺。

当前我国公益服务类设施的建设取得很大进步, 但公 益类科研设施建设仍处在起步探索阶段。已建成的公益类 科研设施还远没有充分发挥其社会价值, 没有真正实现向 普通公众普及科学知识、提高科学技能, 进而成为科学的 主人的科普功能。公民认为科研设施对自己影响不大, 是 科研人员、专业人员才用的到的东西, 公民对公益类科研 设施的认识非常浅显模糊。

\section{2 科普对象科普意识}

目前, 我国公民的文化素质还普遍较低, 还没有在全
民中形成讲知识, 重学问的社会氛围, 随着我国城市化进 程的加快, 更多的农村居民涌入城市, 大多数公民只能满 足自身的物质需求, 科研文化、信息意识十分淡薄, 无法 利用科研设施来帮助自己提升业务能力和技巧, 对于科学 研究持事不关已的态度, 既没有进行科学研究的理论基础, 也没有使用科研设施的实践能力。

我国第八次公民科学素质调查显示, 2010 年, 全国公 民具备基本科研素质的比例为 $3.27 \%$, 每 100 人中, 仅有 3 人具备基本公民科研素质。远低于欧盟、美、日、加拿大 等地区。美国在 2000 年时公众达到基本科研素养水平的比 例已经高达 $17 \%$ 。如果公民缺乏必要的科学素养, 就很容 易被反科学伪科学统摄, 缺乏对科技精神的忠实信仰, 就 容易陷入精神虚空、行为荒唐。《全民科学素质行动计划纲 要》指出, “公民具备基本科学素质, 是指公民了解必要的 科学技术知识, 掌握基本的科学方法, 树立科学思想, 崇 尚科学精神, 并具有一定的应用它们处理实际问题、参与 公共事务的能力。”科学素质已成为与道德素质、身体素质 同等重要的公民素质指标, 因此, 我们应该努力并及时提 供公民的科普意识。一方面, 作为传播公共信息的媒体, 更应该有科普意识, 多开辟“科学”版面, 多关注国内外科 学发展信息, 为公众传播更有价值、实践意义的科技文化 知。另一方面, 公众的精神和文化兴趣, 也应该教育意义 欠缺的花边娱乐新闻、科技含量低的学术新闻中走出来, 多关注科学报道以及科学信息, 提升自己的科普素养, 让 自己成为一个爱科学者。最后, 整个社会应该多倡导“爱科 学, 爱科研”的综合氛围, 比如科研院所应多开展“公众开 放日”, 而不要关起门来自娱自乐。尤其多鼓励孩子树立为 科学献身的崇高理想, 摆脱“精致的利益主义者”的庸俗定 位, 为未来发展注入无穷的科技和发展动力

\section{3 科普媒介存在的问题}

\section{1.科普经费不足}

欧美等西方一些发达国家科普工作资金的来源中企业 起到至关重要的作用, 科技传播普及有助于展示企业自身 的科技实力和企业文化, 因此很多企业参与并开展科普活 动, 投入公益类科研设施的建设, 消费者接受新知识, 了 解新技术, 才会更容易接受新产品。而我国科普工作资金 的来源主要是政府拨款、捐赠和自筹, 公益类科研设施的 建设经费十分欠缺。

\section{2. 科普主体行为和能力缺失}

科研机构为追求直接经济利益, 放弃具有能够带来远 期社会效益的公益类科研设施的建设, 只进行相关科学技 术的转让; 作为科技知识的创造者和传播源的科技人员, 
由于受到以科研成果为核心的考核评价体制的影响, 科普 积极性很低, 科普的效果较差, 科学家们应乐于向媒体和 公众谈论自己的研究工作; 因为缺乏专业教育和职业准入 标准, 目前的科普人员职业化和教育水平相对落后, 有碍 于其学习、理解和传播科技信息。

\section{3.法律体系不完善}

为使我国科普工作走上法制化、制度化的道路, 除了 完善已制定的《科学技术普及法》等法律法规意外, 还应 该制定专项法规和实施细则, 既要有明确的科普组织法、 科普产业化政策, 还应该将科普工作上升到发展战略的层 面上。

\section{3. 完善公益类科研设施科普功能承担的政策、路径}

3.1 加强公民科普意识

强化公益类科研设施公平建设, 加强对科学素养水平 较低群体的关注, 建立以最基本教育保障为基础, 专项补 贴为支撑的公益类科研设施科普体系。建立具有区域特色 的统筹自然资源、科学技术、科技人员、公益类科研设施 的科普框架和体系。强化公益类科研设施建设, 鼓励公益 类科研设施的管理组织创新和制度创新, 发挥公益类科研 设施的科技信息传播与科研实践功能，提升公众科普意识。

\section{2 推进公益类科研设施供给多元化}

公益类科研设施是具有非排他性特点的 准公共产品, 一般来说, 都是由政府参与供给, 因而形成了较强的纵向 一体化政府垄断。为引进竞争、消除这一垄断, 可以采取 合同承包、竞争性招标、特许经营等方式来推进公益类科 研设施供给的多元化, 完成公益类科研设施的建设, 进而 更好的实现其科普功能。

3.3 探索建立财政支持公益科研性设施免费科普的长效机 制

首先, 国家应该加大对公益类科研设施的建设投入, 实现公益类科研设施科普服务均等化, 让更多的公民有机 会学习掌握科学知识、进而运用科学知识进行研究工作。
其次，财政支持公益类科研设施免费科普为公民学习科技 知识、提供公民的整体科研素养提供了可能,为国家加强精 神文明建设, 提高社会整体文明水平提供了有力支持。最 后, 公益类科研设施科普功能的有效实现需要建立在一个 持续稳定的财政支出平台上，政府应有重点、有倾向性的 给予支持, 同时也应该加强与社会其他组织的交流与合作, 争取到更多的财政支持, 让更多的普通公民接触科技信息, 感受科技力量, 进而让更多的人们投入到科学研究的工作 当中, 为国家整个社会的发展提供动力。

\section{4 发展志愿者队伍, 实现公益类科研设施的科普工作}

我国国民经济水平日益提高, 社会主义核心价值观念 深入人心, 志愿者事业的发展已经有了良好的基础。志愿 者活动可以减轻政府对公益类科研设施投资不足而导致公 益科研性设施没有很好利用的现状。因此, 应当进一步完 善志愿者服务制度，加强志愿者服务的培训和回馈机制， 为了激励青少年参加志愿者组织, 可以采取一定的激励政 策, 可以将志愿者参加活动的时间记录下来，建立个人档 案, 将来自己有需要时可以在自己的“道德银行”里以金钱 或互助的形式支取, 以此鼓励和引导志愿者在公益类科研 设施科普功能承担方面提供更深层次、更大范围的服务。

\section{参考文献(References)}

[1] ZHAI Jie-quan, YANG Zhi-jian. "Accelerate the process of scientific communication professional", "Transactions of Beijing Institute of Technology” 2006(5).

[2] Peter Weingart: "Science and the media", "Research Policy", (1998)869-879.

[3] Hou Qing-yun, How to fully understand the meaning of the connotation of "science."? CHINA SCIENCE DAILY, August 28, 1997, 2nd Edition.

[4] Chen Zhen-min, Public Administration. Beijing: China Renmin University Press Co. LTD.2005.

[5] Zhang yunjing. The conception of Chinese History of Science Popularization. Science popularization, pp, 58-62, 2009(6). 